\section{Avaliação da implantação do Método Canguru por gestores, profissionais e mães de recém-nascidos}

\author{
Evaluation of the implementation of Kangaroo Care \\ by health administrators, professionals, \\ and mothers of newborn infants
}

\author{
1 Universidade Federal de \\ São João del-Rei, São João del \\ Rei, Brasil. \\ 2 Faculdade de Medicina, \\ Universidade Federal de \\ Minas Gerais, Belo Horizonte, \\ Brasil. \\ ${ }^{3}$ Escola de Enfermagem, \\ Universidade Federal de \\ Minas Gerais, Belo Horizonte, \\ Brasil. \\ Correspondência \\ T. L. Gontijo \\ Universidade Federal de São \\ João del-Rei. \\ Rua Sergipe 1135, apto. 201, \\ Divinópolis, MG 35500-012, \\ Brasil. \\ enftarcisio@yahoo.com.br
}

\section{Abstract}

This was a qualitative evaluation study aimed at both shedding light on the challenges and facilitating implementation of Kangaroo Care in Ministry of Health-accredited maternity care facilities in Brazil, from the standpoint of healthcare professionals and administrators and mothers of low birth weight newborns. Semi-structured on-site interviews were conducted at the maternity centers. The study used structural narrative analysis with the data analysis method. Key evaluative focal points identified were the method's importance in neonatal care and institutional support for its sustainability. As for the findings, the theoretical concept of institutional analysis was essential for achieving more in-depth reflection. Despite some resistance, the method is being implemented effectively in maternity care facilities; however, the study shows the need for periodic training and more resource allocation to enable improvement in the service's infrastructure, thereby resulting in more effective humanization of care.

Low Birth Weight Infant; Humanization of Assistance; Health Services Evaluation
Tarcisio Laerte Gontijo 1,2

César Coelho Xavier 2

Maria Imaculada de Fátima Freitas 3

\section{Introdução}

Entendido como tecnologia de assistência neonatal que busca, além da melhoria na qualidade da assistência neonatal, a incorporação de práticas de humanização no atendimento a crianças nascidas pré-termo ou com baixo peso, o Método Canguru difundiu-se por diversos países que passaram a incorporá-lo de diferentes formas, de acordo com suas características sociais, econômicas e culturais 1 . Até o ano de 2004, somente no Instituto Materno Infantil de Bogotá, na Colômbia, maternidade pioneira na aplicação do método, equipes de 25 países foram capacitadas para aplicação do mesmo em diferentes partes do mundo 2 .

No Brasil, o Método Canguru difundiu-se rapidamente, a partir de 1990, sendo a proposta brasileira, mais ampla que a proposta originária da Colômbia, abrangendo questões como os cuidados técnicos com o bebê (manuseio, atenção às necessidades individuais, cuidados com luz, som, dor); o acolhimento à família; a promoção do vínculo mãe/bebê e do aleitamento materno; e o acompanhamento ambulatorial após a alta, configurando-se, assim, como estratégia de qualificação do cuidado neonatal 3 .

A norma brasileira determina que o Método Canguru deve ser aplicado em três etapas distintas 4 . A primeira etapa inicia-se no pré-natal de alto-risco, seguido da internação do recémnascido na Unidade Neonatal. Nesse período, 
mãe e família devem ser orientados quanto às condições da criança, ressaltando a importância do Método Canguru. Na segunda etapa, o recém-nascido, após estabilização das condições clínicas, é transferido para a enfermaria canguru, onde ficará acompanhado de sua mãe, que assumirá a posição canguru pelo maior tempo possível, o que permite aumentar a proximidade física e comunicação entre mãe e bebê e o empoderamento materno. Esta etapa funciona como período de adaptação da mãe e do filho para a alta. A terceira etapa começa quando o bebê recebe alta hospitalar e caracteriza-se pelo acompanhamento do bebê e da família no ambulatório e/ou domicílio até atingir o peso de 2.500 gramas. Após alcançar este peso o acompanhamento deve seguir as normas de crescimento e desenvolvimento do Ministério da Saúde. Nem todas as etapas fazem parte da rotina dos serviços públicos ou privados de assistência ao parto, no Brasil, e são vivenciadas diferenciadamente pelas mães, desde a disseminação do Método Canguru no país.

Essa disseminação foi proposta pelo Ministério da Saúde que editou e publicou a Portaria Ministério da Saúde/GM 693/2000 4, estabelecendo a Norma de Atenção Humanizada ao Recém-Nascido de Baixo Peso - Método Canguru (AHRNBP-MC). A partir dela, o Ministério da Saúde realizou, até 2004, cursos de capacitação para profissionais que atendem alto risco em neonatologia. Os cursos foram organizados com 40 horas de duração e desenvolvidos nos Centros de Referência estruturados e organizados pelo Ministério da Saúde, nos quais participavam cinco profissionais de cada maternidade escolhida. Até o ano de 2004, foram capacitados 1.685 profissionais de 293 hospitais maternidade em todo país 5 .

Após a realização desse processo de disseminação, o Ministério da Saúde, em 2006, reuniu dois Grupos de Trabalho para avaliar a experiência brasileira do Método Canguru. O primeiro grupo 6 dedicou-se a avaliar os resultados neonatais desta prática e, ao presente grupo, coube avaliar o processo de implantação do método nas maternidades capacitadas. Este último é o único estudo de abrangência nacional e foi executado em duas fases. Na primeira 5 , buscou identificar o grau de implantação do Método Canguru nas maternidades brasileiras capacitadas e na segunda fase, foram analisados aspectos que interferiram nessa implantação. O presente artigo trata dos resultados dessa segunda fase.

Os achados referentes à primeira fase mostraram que apenas $34,5 \%$ das maternidades capacitadas em todo território nacional implantaram as três etapas do método, conforme recomenda a norma brasileira 5 , havendo baixa incorporação, sobretudo, da terceira etapa. Em outro estudo, que avaliou a implantação do método em maternidades do Estado de São de Paulo, foi identificado um percentual de $46,6 \%$ de implantação das três etapas 7 .

Charpak \& Ruiz-Peláez 2 , em trabalho inédito e singular, avaliaram a implantação do Método Canguru em maternidades de 15 países em desenvolvimento, sendo o único estudo internacional presente na literatura sobre avaliação da implantação do método em diferentes países. Com a análise dos resultados encontrados, identificou-se que o maior obstáculo era também a implantação do acompanhamento ambulatorial, correspondente à terceira etapa no Brasil, além da resistência dos profissionais de saúde, mães e famílias.

Dada a importância do Método Canguru na assistência neonatal, a sua baixa incorporação pelas maternidades brasileiras considerou-se necessário buscar a compreensão sobre aspectos facilitadores e dificultadores da implantação nas maternidades brasileiras capacitadas para este fim. Assim, foram analisados, do ponto de vista dos gestores, profissionais e mães, aspectos que influenciaram a implantação do Método Canguru. A importância do cuidado com a equipe profissional na implantação do Método Canguru não fez parte desta investigação, mesmo reconhecida sua importância.

Este estudo é integrante do projeto de avaliação da implantação do cuidado humanizado aos recém-nascidos com baixo peso - Método Canguru no Brasil, financiado pelo Ministério da Saúde e Organização Pan-Americana da Saúde, a ótica dos gestores, profissionais e mãe está, portanto, no centro deste estudo.

\section{Objetivo}

Compreender dificuldades e facilidades da implantação do Método Canguru em maternidades brasileiras capacitadas pelo Ministério da Saúde, sob a ótica de profissionais de saúde, gestores e mães de recém-nascidos de baixo peso atendidos nesses serviços.

\section{Método}

Trata-se de estudo de avaliação qualitativa. Embora ainda existam debates acerca da adequação do uso de métodos quantitativos e qualitativos na avaliação de serviços de saúde, a abordagem qualitativa na análise de implantação é reconhecida por vários autores 8,9,10 como de grande 
importância para a compreensão das relações entre o grau de implantação e o contexto político e organizacional.

Considera-se que a subjetividade na vivência dos sujeitos envolvidos na implantação tanto está incluída no processo, como implicará os resultados esperados devendo sempre ser incluída nas avaliações. As ideias e atitudes dos profissionais, como das mães participantes, são parte das representações sobre os cuidados e definem decisões sobre implicar-se, mais ou menos, na proposta.

\section{Serviços e sujeitos participantes}

Foi selecionada amostra de hospitais maternidades dentre os 293 capacitados pelo Ministério da Saúde no Brasil entre 2000 e 2003. Para definição dessa amostra adotaram-se os seguintes critérios: não ser maternidade de referência na capacitação do método; ter realizado, no mínimo, 2.000 partos no ano anterior, permitindo assim que, durante as visitas, fossem encontradas mães de recém-nascidos de baixo peso, além de ser localizada em grandes centros urbanos. Assim, obteve-se uma amostra de 29 hospitais maternidade, distribuídos em 20 estados da federação (Tabela 1).

Estes hospitais maternidades receberam visita in loco, no ano de 2005, de um grupo de pesquisadores que, primeiramente, os avaliou, utilizando roteiro estruturado e observação não participante, se a maternidade havia ou não implantado o Método Canguru conforme estabelece a norma brasileira 4 . O método considerou-se como não implantado nas maternidades que não desenvolviam nenhuma etapa; como implantado, naquelas que desenvolviam as três etapas; e, parcialmente implantado naquelas que implantaram apenas uma ou duas etapas.

Tabela 1

Número de hospitais maternidades capacitadas e visitadas na avaliação da implantação do Método Canguru no Brasil.

\begin{tabular}{lccc}
\hline Região & $\begin{array}{c}\text { Maternidades } \\
\text { capacitadas }\end{array}$ & \multicolumn{2}{c}{ Maternidades } \\
& visitadas & $\%$ \\
\hline Norte & 20 & 3 & 15,0 \\
Nordeste & 87 & 9 & 10,3 \\
Centro-oeste & 29 & 3 & 10,3 \\
Sudeste & 102 & 9 & 8,8 \\
Sul & 55 & 5 & 9,1 \\
Total & 293 & 29 & 9,9 \\
\hline
\end{tabular}

Assim, entre os 29 hospitais maternidades visitados, identificou-se que 10 (34,5\%) implantaram o método; 10 (34,5\%) não o implantaram e os outros 9 (31\%) o implantaram parcialmente. A fim de permitir uma adequada avaliação, neste estudo foram analisadas as entrevistas de profissionais, gestores e mães dos hospitais maternidades que implantaram o método e as entrevistas dos mesmos sujeitos naqueles hospitais maternidades que não o implantaram. Para manutenção e garantia do anonimato dos entrevistados, os profissionais foram identificados como $\mathrm{P} 1, \mathrm{P} 2$, P3..., os gestores por G1, G2, G3..., e as mães por M1, M2 e M3...

\section{Instrumento e coleta de dados}

Utilizaram-se cinco diferentes roteiros de entrevistas, devido ao fato de o método ser desenvolvido em diferentes etapas. Para os profissionais atuantes, na primeira e segunda etapa, utilizouse um roteiro, e outro para os que atuavam na terceira. Para as mães, um roteiro para participantes da primeira e da segunda etapas e outro para aquelas que participavam da terceira etapa. Por último, houve um roteiro para a entrevista com os gestores, sendo estes os responsáveis pelo método na instituição.

Os roteiros semiestruturados consistiam de questões norteadoras aos profissionais e gestores, sobre a implantação do método e seu envolvimento na proposta, e às mães, sobre a satisfação com o serviço e os resultados do Método Canguru. As entrevistas foram realizadas durante a visita in loco às maternidades e conduzidas por profissionais especialmente treinados, sendo as mesmas gravadas e transcritas posteriormente.

\section{Análise dos dados}

A análise estrutural de narração 11, apoiada na Teoria Fundamentada nos Dados 12,13, embasou o procedimento de análise do material coletado nas entrevistas.

Considerou-se que tudo, em uma narrativa, tem significado ${ }^{14}$. Nela, o sujeito apresenta fatos, justifica-os, se expõe, retoma ideias e se contradiz, estruturando sua reflexão, ao longo da fala. Desse modo, por mais completa que seja uma análise do conjunto vertical do discurso, para ser eficiente, faz-se necessário realizá-la horizontalmente, uma vez que o sentido não está no fim da narrativa, ele a perpassa 14. Para identificar as interpretações dos sujeitos, a análise das entrevistas foi dividida em três etapas 15 .

A primeira etapa correspondeu à análise de cada entrevista, separadamente. Nessa etapa, o primeiro momento é o de leitura vertical, bus- 
cando o sentido global de cada uma, permitindo conhecer o "tom" da entrevista. Nesse momento, o investigador sintetiza os assuntos tratados, em uma primeira aproximação dos conteúdos. Em um segundo momento da primeira etapa, intitulado "leitura horizontal", o texto de cada entrevista foi dividido em sequências numeradas em ordem crescente, num processo de "desconstrução" textual, desvelando-se os enunciados que explicitam o campo de significados para a pessoa que fala em torno de cada objeto do discurso 16 .

Na segunda etapa, realizou-se a "reconstrução" da entrevista, quando os objetos, explicações e pontos de vista do sujeito foram reagrupados, considerando-se o mesmo assunto abordado na totalidade do relato, para encontrar, acompanhar e reproduzir o trabalho de categorização que o próprio entrevistado realizou. A reconstrução em torno dos objetos é necessária, porque estes se encontram espalhados ao longo da fala, sendo o processo discursivo sempre de idas e vindas para apresentá-los e justificá-los 11,16.

A terceira etapa do trabalho consistiu, no primeiro momento, em encontrar o que é comum e discordante nas categorias explicitadas pelo conjunto de entrevistados, aprofundando a categorização dos significados explicitados sobre os objetos em foco, numa leitura chamada de transversal 15. Em um segundo momento, passou-se à teorização, na qual as categorias surgidas na análise das entrevistas foram aprofundadas por leituras e reflexões teóricas do pesquisador, permitindo o confronto com outros achados e teorias de outros pesquisadores 11 .

\section{Aspectos éticos}

O estudo foi aprovado pelo Comitê de Ética em Pesquisa da Universidade Federal de Minas Ge- rais, constante do parecer $\mathrm{n}^{\circ} .168 / 04$, e o consentimento da participação foi obtido pela leitura, esclarecimento e assinatura do termo de consentimento livre e esclarecido.

\section{Resultados e discussão}

Da amostra de 29 hospitais maternidade no universo de 293 capacitadas para o Método Canguru pelo Ministério da Saúde, encontraram-se 10 que o haviam implantado totalmente e outras 10 instituições que não o implantaram. As entrevistas, com questões abertas e gravadas foram realizadas, conforme a distribuição apresentada na Tabela 2, totalizando 135 entrevistas gravadas em áudio e transcritas em seguida.

Foram duas as categorias centrais identificadas nas falas dos entrevistados: (a) importância do método para a assistência ao recém-nascido; (b) importância do apoio institucional para a sustentabilidade do método. Os discursos dos profissionais e gestores mostraram-se complementares; os das mães, em alguns aspectos, diferenciados desses pelas suas vivências e o lugar que ocupam como atores na institucionalização do Método Canguru.

\section{Importância do método para a assistência ao recém-nascido}

O desenvolvimento de novas tecnologias na neonatologia tem provocado grande impacto na assistência à saúde, nesta área. Por outro lado, gera grande preocupação com a separação precoce e prolongada entre mãe, bebê e família. Assim, a disseminação do Método Canguru, realizada pelo Ministério da Saúde, teve como finalidade sensibilizar profissionais atuantes

Tabela 2

Número de entrevistas realizadas em hospitais maternidades, por categoria de entrevistado, segundo grau de implantação do Método Canguru no Brasil.

\begin{tabular}{lcc}
\hline Entrevistados & $\begin{array}{c}\text { Maternidades que implantaram o } \\
\text { Método Canguru }\end{array}$ & $\begin{array}{c}\text { Maternidades que não } \\
\text { implantaram o Método Canguru }\end{array}$ \\
\hline Gestores & 6 & 8 \\
Profissionais da etapa I e/ou etapa II & 28 & 43 \\
Profissionais da etapa III & 9 & 0 \\
Mães na etapa I e/ou etapa II & 14 & 22 \\
Mães na etapa III & 5 & 0 \\
Total & 62 & 73 \\
\hline
\end{tabular}


na assistência neonatal para o alcance de uma prática humanizadora na assistência ao recémnascido de baixo peso ${ }^{4}$.

Nesse sentido, profissionais e gestores julgam-no como uma tecnologia humanizadora, na qual se implicaram, vivenciando-a a partir da formação e implantação, o que foi mostrado, sobretudo, pela incorporação de conceitos e técnicas de humanização nas maternidades visitadas. Naquelas em que o Método Canguru não foi implantado, mas houve, obviamente, treinamento de profissionais, os discursos também apresentam o reconhecimento da sua importância na assistência ao recém-nascido de baixo peso. Para as mães, a certeza de sua importância para o bebê veio com suas experiências.

“Então, essa questão do vínculo, do apego, o contato pele a pele que garante mais tempo de amamentação (...) também um reforço maior do vínculo..." (G-8).

"Maior afetividade mãe e filho e maior envolvimento entre o binômio mãe e filho. Pra melhoria do desenvolvimento da criança, desenvolvimento afetivo, físico e desenvolvimento até intelectual" (P-25).

Estes relatos estão presentes no discurso dos profissionais, independente da implantação ou não do método na instituição onde atuam, e é o mesmo dentre as falas das mães, apontando, assim, a implicação dos sujeitos no processo de reconhecimento e implantação do Método Canguru como uma nova instituição que vai ganhando corpo na assistência neonatal. Explicitou-se o reconhecimento de que o método traz benefícios importantes para o bebê por meio da interação com sua família, propiciando aumento de vínculo mãe-filho e seu maior desenvolvimento. A implicação 17,18,19 resulta de condições objetivas tais como estrutura, formação, capacitação, apoio institucional, recursos tecnológicos presentes no projeto, e, também, do que Castoriadis 20 denomina "imaginário social”, que é a parte subjetiva das escolhas dos sujeitos, compartilhadas socialmente.

Monceau 19 afirma que a implicação deve ser refletida de uma forma mais abrangente, como a relação que os indivíduos desenvolvem com a instituição, independentemente de ser uma postura crítica, afastada ou inibida, sendo que qualquer uma destas tem efeitos sobre ela. Toda relação com a instituição é, portanto, implicação, sendo que o sujeito decide, mais ou menos, a modalidade e grau de seu envolvimento.

Permeados pelo imaginário social, os indivíduos desenvolvem mecanismos de implicação, objetivados em suas formas de agir e pensar a realidade, aceitando ou recusando o novo, aprendendo com e sobre ele ou se alienando, cri- ticando e/ou integrando-o à sua vida. No caso da implantação do Método Canguru, pressupõe-se que os aspectos subjetivos de aceitação ou recusa dos profissionais de saúde e das mães são tão importantes quanto os funcionais e organizacionais para se levar adiante e haver integração deste nas maternidades brasileiras.

Os profissionais, sobretudo os que estão diretamente ligados ao desenvolvimento das atividades da aplicação do método nas maternidades, apresentam argumentos para reafirmá-lo como proposta viável de assistência neonatal, narrando experiências exitosas e suas vantagens. Dentre estas, sobressaem aquelas relacionadas ao aumento do vínculo entre recém-nascido e família, maior ganho de peso e maior tempo de amamentação exclusiva. Destaca-se que a divulgação dessas vantagens é um dos principais argumentos utilizados pelos profissionais para maior adesão dos pais à proposta, principalmente aquelas referentes ao maior ganho de peso e a alta precoce.

"Porque a gente sempre fala pra colocar no canguru, que é bom, ele vai ganhar peso, que ele vai ficar juntinho de você" (P-41).

“...ela [mãe] fica menos tempo ...o bebê vai ganhar peso, vai sair rápido. São coisas que a gente tem de orientar" (P-4).

Estudos de avaliação tecnológica (observacionais e randomizados), apresentados na literatura internacional, demonstram que o Método Canguru constitui prática segura, trazendo como benefícios a diminuição do tempo de internação, maior ganho de peso diário, maior empoderamento das mães no cuidado ao filho, redução da morbimortalidade, e redução dos custos da internação 21,22,23,24,25,26.

Como a forma de aplicação do Método Canguru está estreitamente relacionada com características sociais, econômicas e culturais de cada país e como a proposta brasileira difere da proposta original 1 , tomamos como referência estudos nacionais sobre a efetividade e aplicabilidade do método que levam em consideração as características brasileiras. Neste sentido, encontram-se poucos estudos na literatura nacional que incluem avaliação de resultados neonatais da aplicação do Método Canguru 6,27,28,29. Além disso, todos eles são do tipo observacionais e a vantagem associada foi maior prevalência do aleitamento materno na alta hospitalar. Os argumentos dos profissionais sobre maior ganho de peso e alta precoce do RN não foram, portanto, ainda confirmados.

No entanto, as representações constantes do imaginário social dos profissionais treinados pelo Ministério da Saúde, aliadas ou não à experiência do dia-a-dia do trabalho, conferem 
significado instituinte ao método na atenção ao recém-nascido de baixo peso, também no Brasil. As ideias instituintes são aquelas inovadoras, que propiciam mudanças ou incremento de tecnologias ou de reorganização social e que serão, aos poucos, aceitas ou rejeitadas nas instituições sociais existentes, como é o caso da implantação do Método Canguru. À luz das teorias da análise institucional 17,19,20, que incluem noções sociológicas e psicanalíticas para a compreensão das mudanças institucionais na sociedade e em suas organizações, pode-se afirmar que o Método Canguru surgiu como inovação tecnológica, buscando instituir uma prática simples de caráter humanizador, em face da utilização cada vez maior de tecnologias duras instituídas nos ambientes hospitalares de neonatologia. Ao mito das tecnologias duras, fundado na crença de que são as únicas resolutivas, com equipamentos e cuidados clínicos de elevada complexidade, surge, portanto, uma tecnologia leve, fundada na interação humana, como também capaz de contribuir para a recuperação e desenvolvimento de recém-nascidos de baixo peso.

Esta força instituinte está presente em análises de outros pesquisadores 2,30 realizadas em outros contextos, e é expressiva nas falas de profissionais e mães entrevistadas, sensibilizados sobre a pertinência dessa tecnologia na atenção ao recém-nascido de baixo peso, seja pelas capacitações e experiências, no caso dos profissionais e gestores, seja pelas informações recebidas e experiências, no caso das mães. Porém, a implementação das práticas do Método Canguru na assistência ao neonato de baixo peso, no Brasil, não ocorreu com esta mesma intensidade, visto que a implantação do método se deu em apenas $34,5 \%$ das maternidades capacitadas pelo Ministério da Saúde 5.

Assim, podemos afirmar que, apesar de o conhecimento teórico sobre a atenção humanizada estar difundido entre os profissionais, ele não foi incorporado plenamente na prática assistencial, mostrando a existência de lacunas entre conhecer e aplicar as mudanças propostas pelo Método Canguru. Tal fato reitera achado de estudos já citados 2,30 que incluem a disjunção entre teoria e prática, também em outros países.

Mesmo em face da constatação de que a prática nas maternidades, em geral, não incorporou a aplicação do Método Canguru, o que aponta para um lugar marginal de sua posição no cuidado ao recém-nascido no país, a análise dos dados confirma o desejo e a percepção de um maior empoderamento dos familiares no cuidado com o bebê. As mães relatam que a experiência de vivenciarem o método na segunda etapa traz maior tranquilidade no manuseio com o bebê, explicitada, sobretudo, nos cuidados posteriores à alta hospitalar, nos casos de maternidades que já haviam implantado a terceira etapa do método. Diversos autores 4,21,28,31,32,33 também apontam que o Método Canguru proporciona maior aquisição, por parte dos pais, de competência e confiança no manuseio de seu filho após a alta.

"Eu acho bom a mãe ir pra casa aprendendo o que eles ensinam porque quando chegar lá não vai ter o médico o tempo todo comigo. Então isso aí pra mim é fundamental, a gente já ir sabendo de tudo" (M-3).

"A gente fica mais tranquila, sabe o que está fazendo. Quando traz o neném para cá [ambulatório], sabe que fez o melhor, né?" (M-18).

A aplicação do Método Canguru envolve, além das questões técnicas, o desenvolvimento de uma proposta de humanização da assistência ao recém-nascido de baixo peso com o intuito de minimizar os efeitos negativos da internação sobre os bebês e suas famílias. Este é um dos motivos da adoção do Método Canguru pelo Ministério da Saúde como uma Política Nacional de Saúde ${ }^{3}$.

As políticas de atenção materno-infantil têm explicitado, cada vez mais, a importância de práticas humanizadoras, visando estabelecer mudanças na atenção ao recém-nascido de baixo peso que promovam melhoria da atenção a ele e à família em busca da melhor qualidade e do vínculo estabelecido entre profissionais e usuários. A incorporação de práticas humanizadoras na assistência neonatal foi outro destaque no discurso dos gestores e profissionais, reforçando o reconhecimento do método como importante para a assistência neonatal.

"Ésuper interessante essa parte da humanização, principalmente. O que a gente puder ajudar pra facilitar esse vínculo da mãe com o bebê. Diminuir essa angústia que é um terror, né?" (G-1).

"A criança tem contato com a voz da mãe, cheiro da mãe, então tudo isso vai favorecer muito a recuperação dessa criança e o equilíbrio emocional dessa criança. A confiança na relação conosco cresce e fica mais fácil para todos nós" (P-29).

A incorporação da humanização traz reflexos significativos na satisfação do cuidado recebido, também do ponto de vista das mães.

"Me senti a mãe mais presente pro filho" (M-1).

"Ah, a proximidade, com certeza, quando boto ele no canguru, eu tenho a certeza de que ele tá cada vez melhor. A gente fica com mais confiança que o que eles [os profissionais] tão dizendo é o certo" (M-2).

Porém, mesmo desvelando-se grande incorporação das vantagens do Método Canguru no discurso dos profissionais, identificam-se profis- 
sionais que resistem à adesão da proposta, que o criticam e não o querem implantado, efetivamente, no serviço. Tais posturas são avaliadas por aqueles que têm o sentimento de "abraçar uma causa”, mas não se sentem apoiados e convivem com a descontinuidade dos procedimentos na mesma unidade.

“As pessoas [profissionais] não acreditam que o canguru funcione e às vezes bloqueia um pouco o procedimento... Então, no tal plantão não vai ter canguru, porque não quer complicação com a criança. Então resiste, tanto com médico como enfermagem tem que tentar vencer essas posturas e tentando passar pras pessoas a necessidade do procedimento, porque se você faz e o restante não, a mãe às vezes até cobra" (P-3).

"Eu acho é que tem muitos funcionários que tem atenção, mas, ao mesmo tempo, tem muitos despreparados, que nem querem aprender" (P-28).

Estudos regionais também apontam como uma das maiores dificuldades na implantação do Método Canguru, a adesão das equipes de saúde que atuam com recém-nascidos pré-termo 7,34. A força instituinte de alguns se confronta com a dificuldade de aceitação do novo, com as posturas instituídas no trabalho que deixam o profissional mais confortável e "cientificamente embasado", sobretudo, porque, não houve, com raras exceções, um grande investimento dos hospitais maternidade, para que o método seja normalizado como regra na atenção ao recémnascido de baixo peso.

Os profissionais que foram capacitados e investiram para a implantação do método em suas unidades, formularam estratégias fundadas na representação de que o interesse dos demais aconteceria devido às vantagens e facilidades do próprio método: "eu faço, os outros se interessarão e vão querer se capacitar também, agregandose com o tempo às atividades", além de lutarem, com frequência, pelo apoio material funcional da instituição hospitalar para a adequação em prol do melhor funcionamento do método. Percebe-se, portanto, que mesmo reconhecendo, em seus discursos, vantagens da aplicação do método, alguns profissionais ainda são resistentes às mudanças de rotinas. Uma maior adesão pode ser facilitada com a consolidação de evidências sobre a eficácia do Método Canguru e com a manutenção de capacitações contínuas e discussão aberta entre os próprios profissionais e com seus gestores.

\section{Apoio institucional}

Estudos apontam a importância do envolvimento dos colaboradores da instituição e a adequação dos recursos físicos e materiais para a implantação do método 7,35,36. Porém, a falta de apoio institucional é um dos aspectos dificultadores mais presentes no discurso dos profissionais e gestores.

“...toda a enfermaria foi feita através de doação externa, doação particular. A gente não teve nem a cama de hospital fornecida pelo próprio hospital" (P-44).

"As dificuldades, eu acho que é a falta de apoio institucional" (G-8).

Nas maternidades que implantaram o método, mães e profissionais que o realizam não apresentam críticas à aplicação do mesmo, conferindo-lhe importância no cuidado ao recém-nascido, como apresentado anteriormente, porém, apontam deficiências nas condições em que o cuidado é oferecido. Entre as principais deficiências apontadas está a falta de espaço físico para adequação do ambiente às necessidades da mãe e bebê, o que acarreta desconforto, além de falta de espaço de convivência.

“...organizar um cantinho que fosse pelo menos adequado, né. Onde a mãe pudesse ter um certo conforto..." (P-19).

“...é a nossa área física que não tá contribuindo. Dentro da área que nós temos real, nós fazemos milagre" (G-6).

A mesma inadequação da estrutura física também foi encontrada em outros estudos, demonstrando a dificuldade de implementação de uma prática assistencial de qualidade 29,37.

No Brasil, a média de dias de internação da mãe e bebê no Método Canguru varia de 20 a 30 dias 6,27,28,32. Este tempo prolongado de permanência hospitalar requer a utilização de espaços confortáveis e o desenvolvimento de atividades ocupacionais. Devido a esse período prolongado de permanência hospitalar é recomendado pelo Ministério da Saúde 4, oferecer às mães e familiares, oportunidades de atividades educativas e de lazer, lúdicas e pedagógicas, direcionadas não só à orientação materna acerca do cuidado com o filho, mas à possibilidade de se integrar aos espaços que são também dela e de seus familiares, associado a um maior conforto. Essas atividades podem amenizar o cansaço materno e otimizar a assistência prestada ${ }^{38}$. Porém, uma das principais deficiências apontadas pelas mães é exatamente, a falta desses espaços e atividades durante a internação.

"Eu achava bom que tivesse alguma atividade pra gente, porque ia ajudar muito, alguma coisa que a gente pudesse fazer" (M-14).

"A única coisa que a gente fazé juntar as mães ali [apontando cadeiras no corredor], às vezes, e ficar conversando com a outra pra distrair um pouco" (M-18). 
A presença de espaços de convivência para que as dúvidas, conflitos e expectativas sejam ouvidos e discutidos entre as mães e com profissionais contribui significativamente para a uma melhor ambientação e permanência da mãe, além da diminuição dos efeitos estressantes durante a internação ${ }^{30}$. Os espaços não devem ser pensados somente como físicos, mas de interação, com rodas de conversas com participação dos profissionais e abordagens variadas de temas ou para receber os familiares, para ler, ver filmes ou para entretenimento na televisão, além, ainda, de espaços de recolhimento, nos momentos de ficar sozinha, ou de descansar. Além disso, deve contar com maior participação dos profissionais de saúde, rompendo com o padrão encontrado de institucionalização do método como um serviço nas margens dessas instituições de atenção ao recém-nascido de baixo peso.

Os resultados obtidos no presente estudo referem-se à fase de implantação do Método Canguru no Brasil que ocorreu até o ano de 2005. Atualmente, o Ministério da Saúde vem desenvolvendo um novo conjunto de ações para sua consolidação como a criação de Centros de Referência Estaduais, encontro nacional de gestores e financiamento do leito canguru.

\section{Considerações finais}

A análise dos discursos permite afirmar que, nas diferentes regiões do país, houve concordância nas representações de mães, gestores e profissionais de saúde de hospitais maternidade sobre a importância da mãe e familiares como parte ativa no processo de recuperação do recém-nascido de risco propiciado pelo Método Canguru. Tal afirmação aponta o fato de que houve disseminação da proposta com as capacitações promovidas pelo Ministério da Saúde. Porém, é importante destacar que há, ainda, enormes desafios a serem enfrentados para que o Método Canguru se torne um instrumento forte nas ações de saúde para o recém-nascido de baixo peso nas maternidades brasileiras. Dentre eles, destaca-se a necessidade de maior apoio institucional, que pode ocorrer com a criação de protocolos pelos próprios profissionais, para o acompanhamento das etapas do método, melhoria da estrutura física e de recursos organizacionais e de pessoal, adequados para uma boa prática.
Os desafios incluem, ainda, as necessidades das mães e familiares no convívio, por vezes prolongado, no interior do serviço hospitalar, e uma assistência social que organize a resposta às necessidades dos demais filhos e familiares enquanto a mãe está ausente. Sem esquecer e colocar no centro das tarefas e de forma contínua, políticas e ações para aumentar a adesão profissional.

Como o Método Canguru é uma política do Ministério da Saúde, o processo de disseminação inicial teve seu foco principal nos profissionais de saúde, buscando habilitá-los como agentes do processo de implantação. É preciso destacar que estes profissionais, na maioria das vezes, não são os tomadores de decisão dentro das instituições. Assim, a sensibilização de gestores é imperiosa, paralelamente à alocação de maiores recursos que permitam melhorar a infraestrutura dos serviços, o que refletirá na humanização do cuidado de forma mais efetiva.

Faz-se necessário, portanto, manter capacitações formais e periódicas para trabalhadores de todos os níveis, inclusive de gestores. Essas capacitações não devem preocupar-se apenas em difundir conhecimentos sobre a aplicação do método ou apenas sensibilizar as equipes para sua importância. Elas devem criar condições para a construção coletiva de projetos efetivos nos serviços, com desenvolvimento de responsabilidades e habilidades que incluam a expressão das subjetividades e julgamentos de valor, para que o conhecimento compartilhado leve à mudança de práticas dos que atuam na assistência ao recémnascido de baixo peso.

Ressalta-se, ainda, que o Método Canguru, além das vantagens clínicas para o bebê, é uma prática segura e prazerosa para mães e familiares, além de propiciar vantagens sociais e psicoafetivas que se encontram no imaginário da institucionalização do método e na experiência das mães quando adequadamente acompanhadas. Tais constatações exigem estudos que possam fundamentar e construir evidências, com parâmetros objetivos, também dessas relevâncias, com monitoramento do Método Canguru no Brasil.

Por último, vale destacar, a necessidade de realização de novos estudos de avaliação dos resultados neonatais considerando a proposta brasileira, consolidando assim, cada vez mais as vantagens da aplicação do Método Canguru em nosso país para a sua efetiva implantação. 


\section{Resumo}

Trata-se de estudo de avaliação qualitativa que buscou compreender dificuldades e facilidades da implantação do Método Canguru em maternidades brasileiras capacitadas pelo Ministério da Saúde sob a ótica de profissionais de saúde, gestores e mães de recém-nascidos de baixo peso atendidos nesses serviços. Realizaram-se entrevistas semiestruturadas durante visita in loco as maternidades. Utilizou-se a análise estrutural de narração como método de análise dos dados. Os principais núcleos avaliativos centrais identificados foram: importância do método para a assistência ao recém nascido; importância do apoio institucional para a sustentabilidade do método. Para o aprofundamento da reflexão sobre os resultados encontrados, o referencial teórico da análise institucional foi fundamental. Apesar das resistências, a institucionalização do método está sendo realizada nas maternidades, porém, há necessidade de se manter capacitações periódicas e de se alocar maiores recursos que permitam melhorar a infraestrutura dos serviços, refletindo na humanização do cuidado de forma mais efetiva.

Recém-Nascido de Baixo Peso; Humanização da Assistência; Avaliação de Serviços de Saúde

\section{Colaboradores}

T. L. Gontijo contribuiu para a concepção, coleta e análise dos dados e aprovou a versão final. C. C. Xavier contribuiu para a concepção, aquisição e análise dos dados, realizou a revisão crítica do conteúdo e aprovou a versão final. M. I. F. Freitas contribuiu para a concepção e análise dos dados, realizou a revisão crítica do conteúdo e aprovou a versão final.

\section{Agradecimentos}

Organização Pan-Americana da Saúde e Ministério da Saúde.

\section{Referências}

1. Charpak N, Ruiz-Peláez JG, Figueroa de Calume Z. Current knowledge of Kangaroo Mother Intervention. Curr Opin Pediatr 1996; 8:108-12.

2. Charpak N, Ruiz-Peláez JG. Resistance to implementing Kangaroo Mother Care in developing countries, and proposed solutions. Acta Paediatr 2006; 95:529-34.

3. Lamy ZC, Gomes MASM, Gianini NOM, Hennig MA. Atenção humanizada ao recém-nascido de baixo peso - Método Canguru: a proposta brasileira. Ciênc Saúde Coletiva 2005; 10:659-68.

4. Ministério da Saúde. Portaria GM/MS nº. 693, de 5 de julho de 2000. Norma de atenção humanizada ao recém-nascido de baixo peso. Diário Oficial da União 2000; 6 jul.

5. Gontijo TL, Meireles AL, Malta DC, Proietti FA, Xavier CC. Evaluation of implementation of humanized care to low weight newborns - the Kangaroo Method. J Pediatr 2010; 86:33-9.

6. Lamy Filho F, Silva AA, Lamy ZC, Gomes MA, Moreira ME. Evaluation of the neonatal outcomes of the kangaroo mother method in Brazil. J Pediatr 2008; 84:428-35.
7. Colameo AJ, Rea MF. O método mãe canguru em hospitais públicos do estado de São Paulo, Brasil: uma análise do processo de implantação. Cad Saúde Pública 2006; 22:597-607.

8. Denis J, Champagne F. Análise da implantação. In: Hartz ZMA, organizadora. Avaliação em saúde: dos modelos conceituais à prática na análise de implantação de programas. Rio de Janeiro: Editora Fiocruz; 1997. p. 49-88.

9. Hartz ZMA, Champagne F, Contandriopoulos A, Leal MC. Avaliação do programa materno infantil: análise de implantação em sistemas locais de saúde nordeste do Brasil. In: Hartz ZMA, organizadora. Avaliação em saúde: dos modelos conceituais à prática na análise de implantação de programas. Rio de Janeiro: Editora Fiocruz; 1997. p. 89-131.

10. Patton MQ. Qualitative research and evaluation methods. Thousand Oaks: Sage Publications; 2002.

11. Demazière D, Dubar C. Analyser les entretiens biographiques, l'exemple de récits d'insertion. Paris: Essais \& Recherches; 1997. 
12. Strauss A, Corbin J. Basics of qualitative research: grounded theory procedures and techniques. Newbury Park: Sage Publications; 1990.

13. Strauss A, Corbin J. Grounded theory in practice. Thousand Oaks: Sage Publications; 1997.

14. Barthes T. A aventura semiótica. São Paulo: Editora Martins Fontes; 2001.

15. Blanchet A, Gotman A. L'enquete et ses méthodes: l'entretien. Paris: Nathan; 1992.

16. Freitas MIF. A gestão do segredo na vida de casais após a infecção pelo HIV. Belo Horizonte: Universidade Federal de Minas Gerais/Programa de Cooperação Técnica SIDA Brasil - França; 1998.

17. Lourau R. L'analyse institutionelle. Paris: Éditions de Minuit; 1970.

18. Crozier M, Friedberg E. l'acteur et le systeme. Paris: Éditions du Seuil; 1977.

19. Monceau G. Implicação, sobre implicação e implicação profissional. Fractal Rev Psicol 2008; 20: 19-26.

20. Castoriadis C. L'institution imaginaire de la société. Paris: Éditions du Seuil; 1975.

21. Conde-Agudelo A, Belizán JM, Diaz-Rossello J. Kangaroo mother care to reduce morbidity and mortality in low birthweight infants. Cochrane Database Syst Rev 2011; (3):CD002771.

22. Feldman R, Eidelman AI, Sirota L, Weller A. Comparison of skin-to-skin (kangaroo) and traditional care: parenting outcomes and preterm infant development. Pediatrics 2002; 19:16-26.

23. Feraudy PY. Manejo ambulatório del recien nacido de bajo peso - Madre Canguro. Rev Soc Boliv Pediatr 2001; 30:68-75.

24. Charpak N, Ruiz-Peláez JG, Figueroa de Calume Z, Charpak Y. A randomized, controlled trial of kangaroo mother care: results of follow-up at 1 year of corrected age. Pediatrics 2001; 108:1072-9.

25. Charpak N, Ruiz-Peláez JG, Figueroa de Calume Z, Charpak Y. Kangaroo mother versus traditional care for newborn infants $£ 2000$ grams: a randomized controlled trial. Pediatrics 1997; 100:682-8.

26. Bell RP, McGrath JM. Implementing a research based Kangaroo care program in the neonatal intensive care unite. Nurs Clin North America 1996; 31:387-403.

27. Brito MHA. Modelos de assistência neonatal: comparação entre o método mãe canguru e método tradicional [Tese de Doutorado]. São Paulo: Universidade de São Paulo; 2008.
28. Rodrigues MAG, Cano MAT. Estudo do ganho de peso e duração da internação em recém-nascido pré-termo de baixo peso com a utilização do método canguru. Rev Eletrônica Enferm 2006; 8:185-91.

29. Freire NB, Garcia JB, Lamy ZC. Evaluation of analgesic effect of skin-to-skin contact compared to oral glucose in preterm neonates. Pain 2008; 139:28-33.

30. Henning MAS, Gomes MASM, Giannini NOM. Conhecimentos e práticas dos profissionais de saúde sobre a Atenção Humanizada ao Recém-Nascido de Baixo Peso - Método Canguru. Rev Bras Saúde Matern Infant 2006; 6:427-35.

31. Cabral IV, Rodrigues EC. O método mãe canguru em uma maternidade do Rio de Janeiro 2000-2002: necessidades da criança e demanda de educação em saúde para os pais. Texto Contexto Enferm 2006; 15:629-36.

32. Toma TS. Método Mãe Canguru: o papel dos serviços de saúde e das redes familiares no sucesso do programa. Cad Saúde Pública 2003; 19:233-42.

33. Javorski M. Os significados do aleitamento materno para as mães de prematuros em cuidado canguru [Tese de Doutorado]. Ribeirão Preto: Universidade de São Paulo; 1997.

34. Rodrigues MAG, Cano MAT. Estudo do ganho de peso e duração da internação em recém-nascido pré-termo de baixo peso com a utilização do método canguru. Rev Eletrônica Enferm 2006; 8: 185-91.

35. Parisi TCH, Coelho ERB, Melleiro MM. Implantação do método mãe canguru na percepção de enfermeiras de um hospital universitário. Acta Paul Enferm 2008; 21:575-80.

36. Costa R, Monticelli M. O método mãe canguru sob o olhar problematizador de uma equipe neonatal. Rev Bras Enferm 2006; 59:578-82.

37. Neves FAM, Orlandi MHF, Sekine CY, Skalinski LM. Assistência humanizada ao neonato prematuro e/ou de baixo peso: implantação do Método Mãe Canguru em hospital universitário. Acta Paul Enferm 2006; 19:349-53.

38. Furlan CEFB, Scochi CGS, Furtado MCC. Percepção dos pais sobre a vivência no método mãe-canguru. Rev Latinoam Enferm 2003; 11:444-52.

Recebido em 22/Ago/2011

Versão final reapresentada em 17/Jan/2012 Aprovado em 02/Fev/2012 